Document downloaded from:

http://hdl.handle.net/10251/162254

This paper must be cited as:

Carrasco, P.; Bendaña, R.; Paredes, A.; Michinel, H.; Fernández De Córdoba, P.; Arce, ME.; Zaragoza, S. (2020). Analysis of key variables for energy efficiency in warships. Journal of Engineering for the Maritime Environment. 234(1):26-36.

https://doi.org/10.1177/1475090219864816

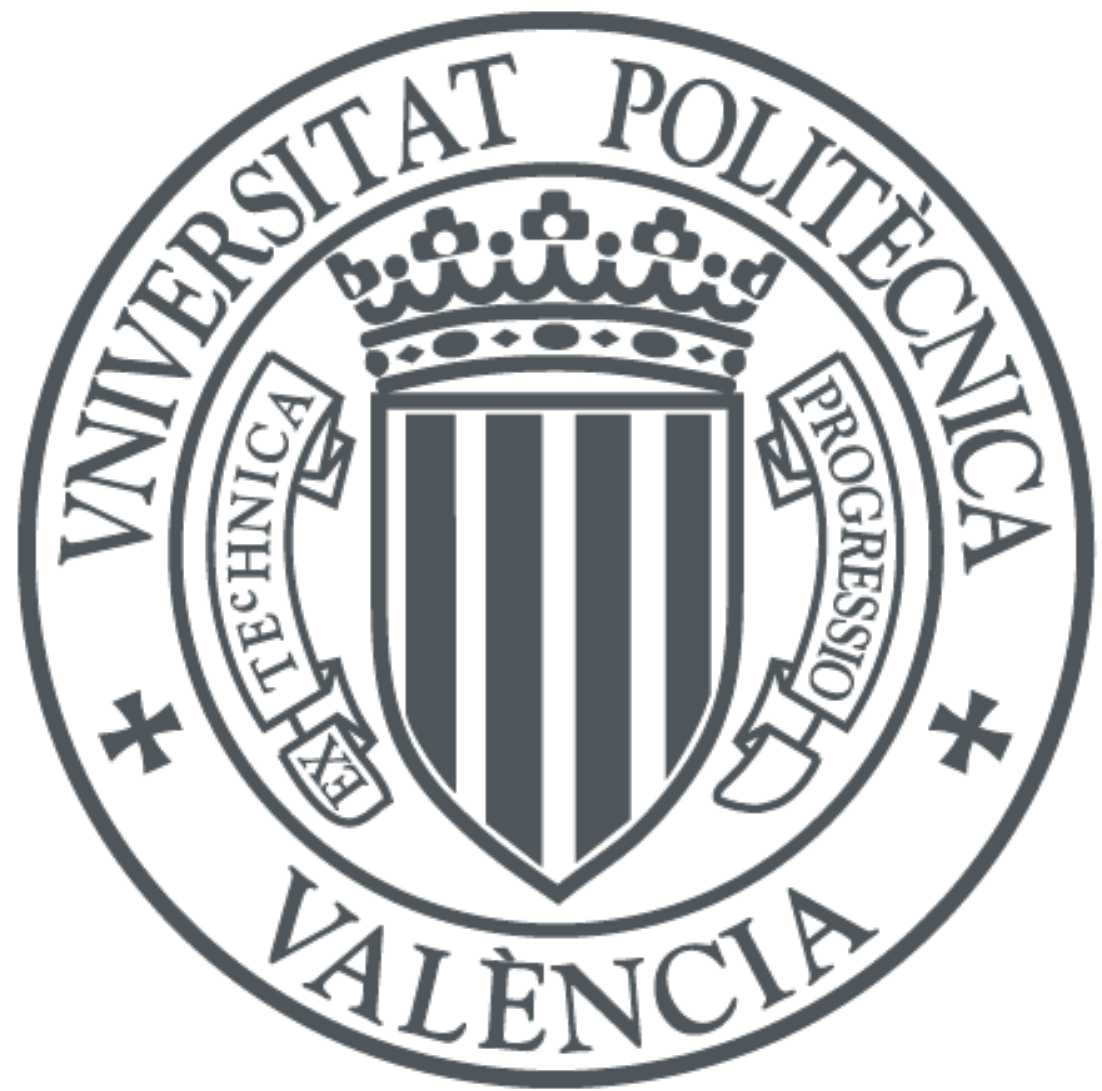

The final publication is available at

https://doi.org/10.1177/1475090219864816

Copyright Sage

Additional Information 


\title{
Analysis of key variables for energy efficiency in warships.
}

\section{Pedro Carrasco ${ }^{1}$, Ricardo Bendaña ${ }^{2}$, Angel Paredes ${ }^{2}$, Humberto Michinel ${ }^{2}$, Pedro Fernández de Córdoba ${ }^{3}$, M. Elena Arce ${ }^{4}$, and Sonia Zaragoza ${ }^{5}$}

\begin{abstract}
The purpose of this work is to investigate the effect of environmental variables on the electric energy expenditure of a typical surface warship. Studies with similar objectives are much more frequent for merchant ships, but warship operations have peculiarities that will be emphasized. In particular, they spend large fractions of their life cycle at port, during which the vessel remains active. Firstly, a discussion of the embarked systems is presented, pointing out the importance of auxiliary systems and in particular, heating, ventilation and air conditioning. Quantitative estimates of the energy consumption of those systems are provided. Then, using data taken during real operations of a frigate of the Spanish navy, correlations are computed between power consumption and different environmental variables. As a novelty, the analysis is carried out separating the different modes of operation of the ship. This leads to interesting conclusions, including a considerable positive correlation between sea water temperature and consumption when the vessel is at port. The effect of a moored ship on the surrounding sea water temperature is studied by a numerical computation. The results suggest that the position of sea chests may be consequential for energy efficiency.
\end{abstract}

\section{Keywords}

Warships, Energy efficiency, Statistical correlations, HVAC, numerical simulation

\section{Introduction}

Energy Efficiency (EE) is essential in all aspects of human activity. This work analyzes the energy consumption of a surface warship under real operation conditions. Around $80 \%$ of the world's transport by volume is done by sea [1] whereas approximately $4 \%$ of the world's ships are warships [2]. Understanding the factors determining energy expenditures is a first step towards the design and utilization of increasingly efficient vessels [3], while maintaining appropriate safety standards [4]. Schemes like Multi-Criteria Decision Analysis (MCDA) have been widely applied in recent times [5].

Since the late twentieth century, studies in the field of EE improvement in warships have been mainly promoted by naval forces like the US Navy [6, 7] or the Royal Navy [8]. The aim is to obtain cheaper units both in its construction and its operation life, seeking $\mathrm{EE}$ and respect for the environment [9]. Versatile models that allow for consumption monitoring and prediction under different circumstances are valuable [10]. From statistical analysis, it is possible to define quantifiable parameters describing the behavior of the embedded systems, establishing lines for their optimization [11].

However, the literature and the availability of data for warships are scarce. The main goal of this contribution is to point out the disparities between warships and merchant ships in what respects electric energy consumption. An important difference is the longer periods that warships spend at port. That implies that in this case more attention should be paid to shore conditions.
First, the electric loads of a typical frigate are discussed. It is shown that the Heating, Ventilation and Air Conditioning systems (HVAC) play a prominent role for the analysis of power consumption. Then, data measured during the operation of a ship of the Spanish navy are analyzed applying techniques of preliminary treatment of energy data [12]. In particular, the method chosen is the calculation of Pearson's coefficient, that measures the degree of correlation between different variables. This type of correlation has been widely used in, e.g., the quantification of the dependence between connected processes in both civil engineering [13] and shipbuilding, mostly in reference to engines [14]. Since the main motivation of the present work is $\mathrm{EE}$, the computed correlations are those of power consumption with quantities such as ambient temperature, sea water temperature, indoor temperature and ambient relative humidity. These variables affect the functioning of the systems in several ways. For instance, the HVAC uses sea water for its internal processes. Notice that other variables such as wind velocity or direction

\footnotetext{
${ }^{1}$ IUMPA, Universidad Politécnica de Valencia, Spain

${ }^{2}$ School of Aeronautic and Space Engineering, Universidade de Vigo, Spain

${ }^{3}$ IUMPA, Universidad Politécnica de Valencia, Spain

${ }^{4}$ Centro Universitario de la Defensa, Escuela Naval Militar de Marín, Spain

${ }^{5}$ Escola Politécnica Superior, Universidade de A Coruña, Spain
}

\section{Corresponding author:}

Sonia Zaragoza, Escola Politécnica Superior, Universidade de A Coruña, Rúa Mendizábal s/n, 15403 Ferrol, Spain

Email: szaragoza@udc.es 
have been considered in recent studies [15] but are not taken into account here.

Apart from the overall analysis of the data, the study is also performed as a function of the mode of operation of the vessel. Unsurprisingly, the needed supply of electricity severely depends on the operation mode. Thus, from a statistical point of view, it is natural to introduce the variable in the description. This is of particular interest for warships, since they spend a large fraction of their life in ports, as compared to merchant ships. The two essential novelties of the present contribution with respect to previous statistical analyses of fuel consumption [16] and $\mathrm{CO}_{2}$ emissions [17] in surface ships are that data were measured for a warship and that operation modes are taken into account.

Within the studied variables, the temperature of sea water plays a prominent role. Correlations do not directly reveal cause-effect relationships and, apart from the effect of sea water temperature on the embarked systems, a moored vessel affects the water temperature in its vicinity. A numerical study of heat diffusion in a particular situation is presented to illustrate this point. The results are interpreted using statistical and physical analysis in combination, and potential improvements towards EE are identified. From a general perspective, our results suggest that this type of analysis can shed new light on the observed phenomena, paving the way for the design of strategies for reducing power consumption.

\section{Description of the warship and its electric consumption}

\section{General considerations for warships: definition and modes of operation}

Warships consist of two fundamental parts [18]: the Combat System (CS), which is the payload of the vessel; and the platform, composed of the base structure on which the rest of equipment and main services are installed and the place where the crew members develop their work. The Integrated Platform Control System (IPCS) has the task of controlling and regulating all the systems of the platform, including those related to propulsion.

Two types of consumption must be distinguished in general [19]: the power dedicated to the propulsion of the ship and the rest. It is fundamental to estimate the necessary power in order to dimension the propulsion systems and the power needed for the different electrical and electronic consumers installed [20]. With this goal, it is convenient to define the Electric Load Conditions (ELC) through the Electric Power Load Analysis (EPLA) [21]. The systems used and the power needed in the warship largely depend on the mode of operation at any given time. The modes are classified in the DDS 310 norm [22] and are:

1. Anchor: a mode of operation of the ship in which it supplies all the electrical energy, while the vessel is anchored at sea.

2. Shore: an operating mode in which the ship is at port. It must be stressed that warships in port are not inactive; tests are done, as well as maintenance works, logistics, personnel management etc., involving significant power expenditures. It can be subdivided as: a. Shore off: Power is supplied by an external electricity network.

b. Shore on: When ships are securely moored in a port, it is not always possible to take the electrical energy from an external installation. This mode corresponds to a situation in which power is supplied by the ship's power plant.

3. Cruising: a mode of operation of the vessel related to economy or cruising speed navigation. The ship is moving from one point to another.

4. Functional: a working mode in which the boat is performing the functions for which it has been designed.

5. Emergency: a mode of operation of the ship in which the vital equipment related mainly to navigation, maneuvers, weapons and communications is in operation.

Apart from the operation modes, seasonality (summer/winter) can be taken into account for calculations [23]. Therefore, two ELCs can be defined for each operation mode. In the case of warships, the division into the different groups of consumers is done on the basis of an analytical structure called the "Expanded Ship Work Breakdown System" (ESWBS), which was created by the United States and adopted by the NATO countries as a unifying element [7].

\section{The warship used in the study}

The surface warship on board of which the data were taken is a "Combatant" type vessel of the Spanish navy (see Fig. 1). Its main dimensions are: 146.69 meters in length overall, 18.60 meters of beam and 9.80 meters of molded depth. The maximum displacement is 6,391 tons and the number people on board is around 200-235. Similar vessels are present in the navy of numerous nations like Australia and Norway. Ships of this type conform the backbone of fleets nowadays, participating in practically every mission.

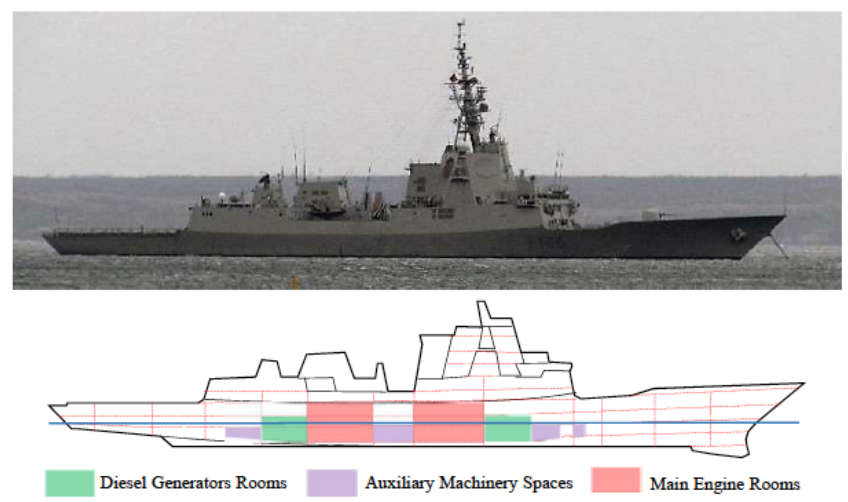

Figure 1. Top: photo of the frigate. Bottom: sketch of the ship.

For its propulsion, this frigate has a Combined Diesel or Gas plant, consisting of two naval General Electric LM2500 turbines of 17,500 kW each and two BAZAN diesel engines of $6,000 \mathrm{~kW}$ each, distributed in two engine rooms. Electricity for the rest of systems is supplied by four diesel generating units of $1,200 \mathrm{~kW}$ each, distributed in two rooms. 


\section{Ship's power distribution and breakdown}

ELC calculations are based on data from equipment manufacturers and are classified based on ESWBS. This classification groups the equipment and systems into seven families, numbered from 100 to 700 . The first one corresponds to the steel and structure of the ship or platform and the rest of them to the equipment and systems installed on the platform, including all the electric consumers.

An analysis of the Combatant F-105 frigate based on the relevant technical specifications of the shipyard documentation shows that there are a total of 1,600 consumers that add up to $9,015 \mathrm{~kW}$ installed. They are broken down in the ESWBS groups as follows:

- 200 Propulsion $483 \mathrm{~kW}$

- 300 Electric plant $174 \mathrm{~kW}$

- 400 Command and control 1,623 kW

- 500 Auxiliary systems 5,322 kW

- 600 Equipment and furnishings $983 \mathrm{~kW}$

- 700 Armament $430 \mathrm{~kW}$

These values are represented in Fig. 2, which shows that the consumers corresponding to the group of auxiliary systems (500) are the most important ones, representing 59\% of the total installed load.

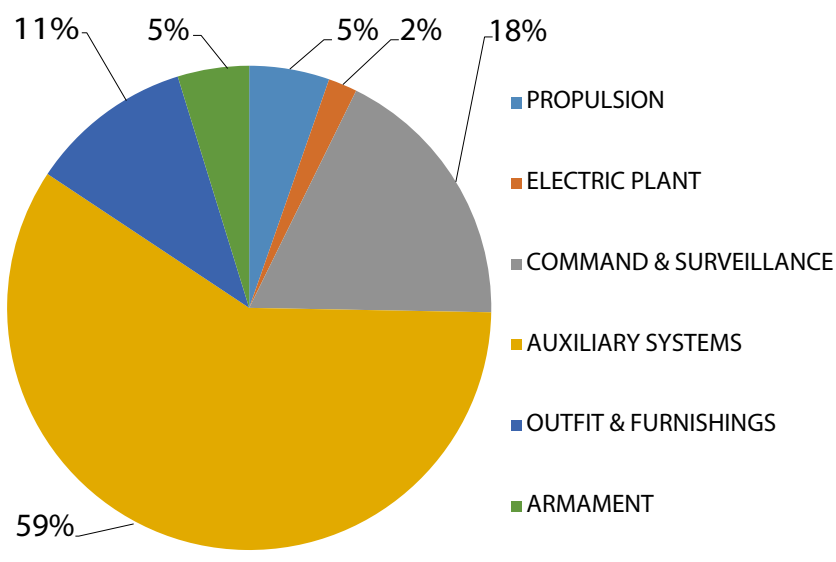

Figure 2. Proportional distribution of the total installed electric load.

A neat difference between warships and merchant ships is that the former typically spend more than half of their time in port, whereas the latter tend to minimize their stays at ports in order to optimize their economic outcomes. It is therefore interesting to carefully analyze the consumption of warships under the shore, static, conditions (notice that most studies in the maritime sector focus on navigation because they are aimed at reducing the consumption of propulsion engines). In Fig. 3, an estimation of the consumption under the different ELCs is plotted. The estimation was calculated using the commonly accepted standards (DDS, NAVSEA) and the manufacturer's operating parameters information of the different components, equipment and systems on board. The graph represents the calculated values of electric charge that are used to estimate the specific energy needs of the ship in each mode of operation. A stable condition, isolated from transitions, or weather variations is assumed.
The emergency mode, being an extreme situation in which criteria of EE are not relevant, is not included. The graph shows that the group 500 of auxiliary systems is the one requiring the highest energy expenditure in all the ELCs defined in the EPLA. It is particularly predominant for the shore and anchor modes. Special attention should be paid to port situations in Winter where the consumption of the group 500 accounts for $75 \%$ of the total.

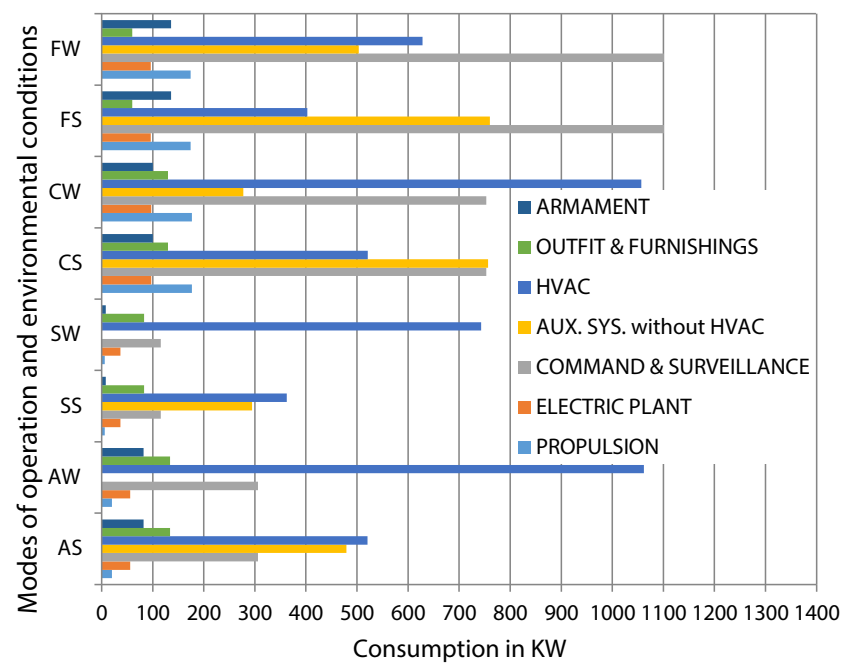

Figure 3. Estimated energy consumption for the different ELCs, grouped by consumer sectors. The operating modes are F (functional), C (cruising), S (shore), A (anchor). Climatic conditions are taken as $\mathrm{S}$ (summer) and $\mathrm{W}$ (winter) - i.e. FW means "Functional winter". The graph has been elaborated using the technical documentation of the shipyard, with the specifications for construction.

\section{Quantitative estimates for HVAC consumption}

Among the auxiliary systems, special attention must be paid to the HVAC, which is crucial to dissipate the heat generated by the different systems, creating the optimal conditions for the operation of the different devices and for the comfort for the crew members working on board. It operates continuously under any ELC. The HVAC represents a percentage of between $18 \%$ and $57 \%$ of the total electric consumption, see Fig. 4.

In order to estimate the annual consumption of the HVAC system of the warship, we assume that it is splits its time between summer and winter conditions and consider the it spends the following fractions of time for the different modes: $50 \%$ at shore, $10 \%$ functional, $10 \%$ anchor and $30 \%$ cruising, which correspond to typical values [24, 25]. Then, the annual energy consumption of the HVAC is of the order of $5 \times 10^{6} \mathrm{kWh}$, around $40 \%$ of the total. Thus, the group 500, and in particular the HVAC system, are important elements to optimize in the search for improved EE in warships.

\section{Data collection and trend analysis}

\section{Sensors and interface}

The embarked devices that monitor the environmental conditions include. One sensor for air temperature $\left(T_{a}\right)$, with 


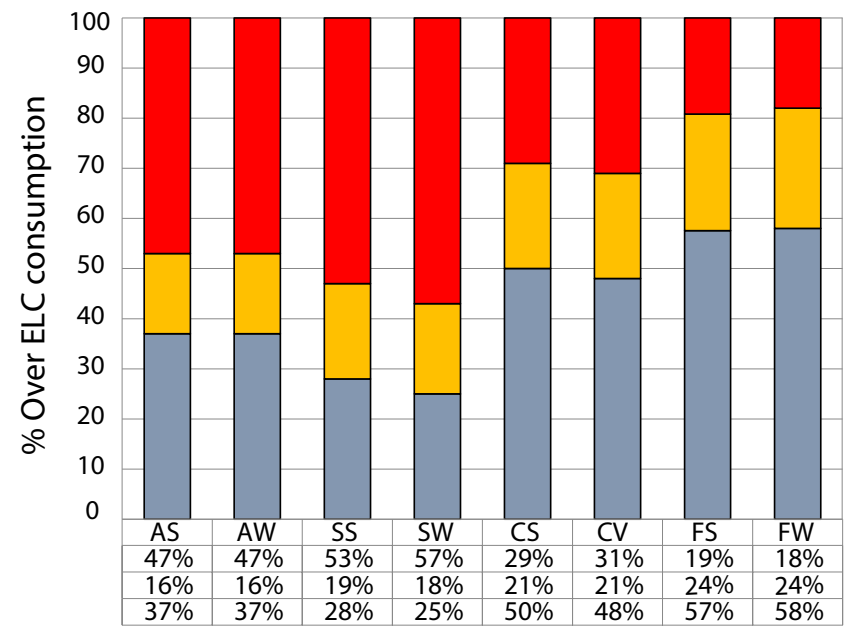

Figure 4. Estimated energy consumption for the different ELCs (see caption of Fig. 3), where the HVAC system is considered separately. The upper red bars correspond to the 510 HVAC group, the intermediate yellow bars to the 500 group except the HVAC and the lower gray bars to the rest of groups $(200,300$, $400,600,700)$.

an uncertainty of $\pm 0.3^{\circ} \mathrm{C}$ an one for relative humidity $(R H)$, with an uncertainty of $\pm 1 \%$ at $23{ }^{\circ} \mathrm{C}$. The interface system includes a Meteorological Interface Unit (MIU) that collects the electronic signals from all the sensors and sends the data to the meteorological data computer. Figure 5 shows the location of the sensors. All the sensors are installed on the mast in order to avoid obstacles and the effect of the exhausted gases.

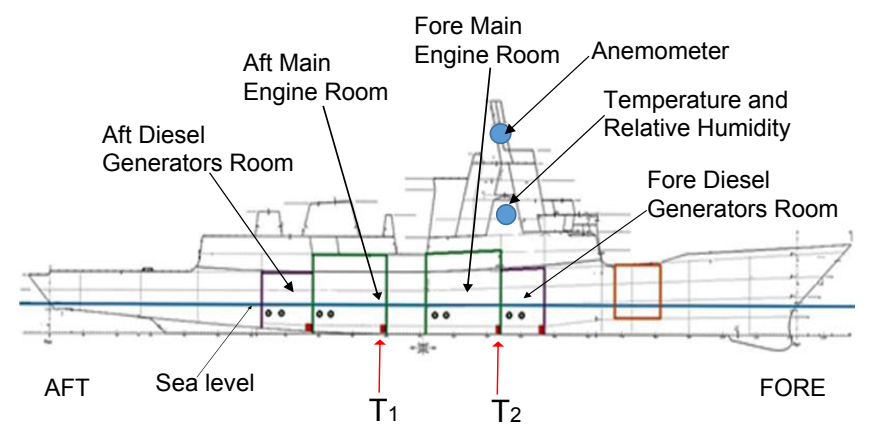

Figure 5. Scheme of the ship specifying the position of the weather station, engine rooms and the sea chests (red arrows) where the temperature sensors are placed.

The F-100 ships have an IPCS where all data are collected, recorded and managed. The general scheme for the data collection is shown in Fig. 6. The measurements are carried out for all variables using Remote Terminal Units (RTU). Groups of signals are sent from them to the central computer, which, in turn, sends them to the IPCS. Then, they can be extracted using the human interface control stations. The system allows for real time monitoring of all the variables.

\section{Data acquisition}

The data were collected during eight days of operation of the frigate. The period runs between 12:00 of the first day and 12:00 of the ninth day and measurements were performed

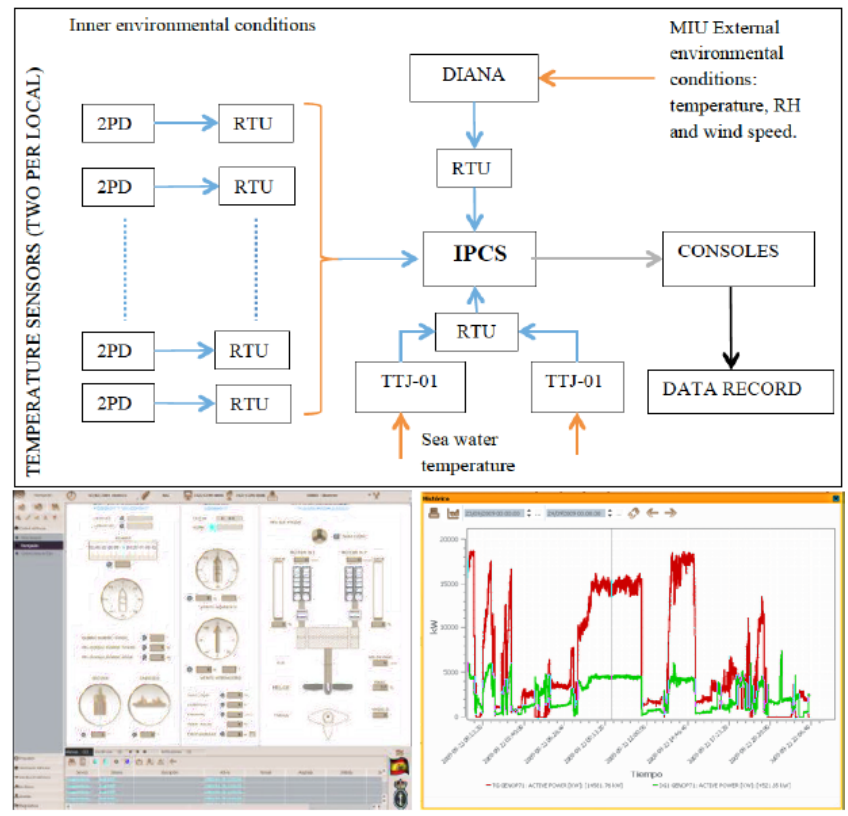

Figure 6. Top: A scheme of the installed data collection system. The devices names 2PD are thermocouples that work as thermometers. The TTJ - Temperature Transmission Junction - items measure sea water temperature in real time. Bottom left and right: screenshots of the main control panel and data output, respectively.

every hour. Climatological conditions were intermediate between summer and winter and did not change appreciably. As it is shown in Fig. 7, except for the "shore on" mode that we will analyze in detail later, the temperature of the sea $T_{s}$ slightly oscillates around an average value of $14,4^{\circ} \mathrm{C}$. Thus, seasonality is not taken into account in the definition of the ELCs. On the other hand, during the period, the ship operated in all the different modes except the emergency one, see table 1. The studied period can be considered as representative of typical operations.

\begin{tabular}{|l|c|r|}
\hline Operation Mode & Hours & $\mathbf{( \% )}$ \\
\hline Shore off & 48 & $25 \%$ \\
\hline Shore on & 73 & $38 \%$ \\
\hline Total Shore & $\mathbf{1 2 1}$ & $\mathbf{6 3 \%}$ \\
\hline Anchor & 11 & $6 \%$ \\
\hline Cruiser & 46 & $24 \%$ \\
\hline Function & 14 & $7 \%$ \\
\hline Total Sea & $\mathbf{7 1}$ & $\mathbf{3 7 \%}$ \\
\hline Total & $\mathbf{1 9 2}$ & $\mathbf{1 0 0 \%}$ \\
\hline
\end{tabular}

Table 1. Elapsed time, in hours, per operation mode.

The data included in the analysis correspond to the following quantities:

- Electrical power consumption of the vessel $\left(P_{e}\right)$, not including the expenditure of the propulsion engines.

- Ambient temperature $\left(T_{a}\right)$ and relative humidity $(R H)$, taken from the ship's weather station, that is installed in the antennas pole, see Fig. 5.

- Engine room temperature $\left(T_{e r}\right)$, taken from the IPCS. There are two thermometer sensors in each engine 
room, one near the top and one near the bottom. The mean value is recorded by the IPCS. We use the average of the two engine rooms.

- Sea water temperature $\left(T_{s}\right)$, taken from the IPCS. It corresponds to the water inlet through the sea chests, see Figs. 5 and $6 . T_{s}$ is the average of the data measured from all the sensors.

The temporal series of data for these five variables is depicted in Fig. 7, that also shows the periods for which the warship was operating under the different modes.

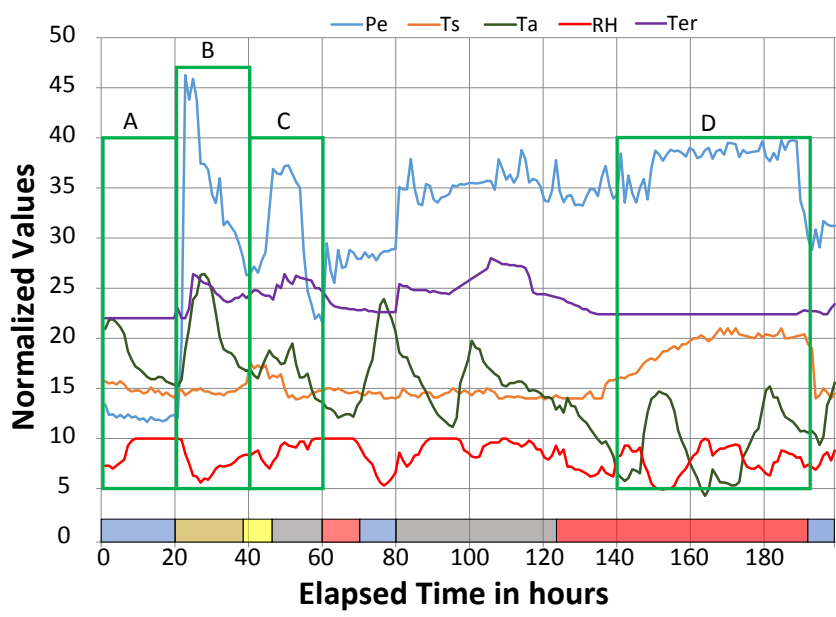

Figure 7. Time evolution of the studied variables. $T_{s}, T_{a}, T_{e r}$ are given in Celsius. The other two quantities have been rescaled in order to refer all of the variables to the same vertical axis and the plot depicts the normalized values $R H / 10$ and $P_{e}(k W) / 10$. The bar on the bottom identifies the ELCs. The code is: yellow (anchor), gray (cruising), red (shore on), blue (shore off), brown (functional).

Before performing a quantitative statistical analysis, it is interesting to remark some qualitative features that can be readily observed from Fig. 7. Four particular time lapses have been framed and named A, B, C, D, in order to facilitate the following discussion.

The lowest consumption corresponds to frame A, in a shore off mode. Most systems are turned off, being the HVAC the most important consumer in this condition. In functional mode, cf. frame $\mathrm{B}$, the highest consumption peaks appear, due to the increased number of devices in use and to the high demand for cooling of the CS electronics. Frame $\mathrm{C}$ includes the anchor and cruising modes. Electrical consumption decreases under the anchor mode because most equipment is turned off, but there is a rise in seawater temperature. Consumption then grows with the entry in cruising mode, when more equipment is in use. A gradual drop in seawater temperature starts at this point. The frame $\mathrm{D}$ corresponds to a condition of shore on that presents a rise of the $P_{e}$ and $T_{s}$ curves with very similar tendencies.

Comparing the different curves for both the external and internal environmental conditions of the premises (engine room), the sea water temperature curve is the one presenting the most similar trends to the consumption curve. This observation will be born out by the analysis of the next section and gives evidence on the interest of the joint study of these parameters.

\section{Statistical analysis}

In this section, the value of the Pearson correlation coefficient $r \in[-1,1]$ for a series of variable pairs will be computed. It gives an indication on how the different values affect the consumption of the ship. The Pearson coefficient assumes a linear regression model and it has been chosen for simplicity. It is possible to use other statistical indicators such as the non-parametric Spearman correlation, which only assumes a monotonic, not necessarily linear, relation between variables. The general features of the analysis hold also in that case. The pairs of variables considered in the analysis are the following ones: $P_{e} \sim T_{s}, P_{e} \sim T_{a}$, $P_{e} \sim R H, P_{e} \sim T_{e r}, T_{s} \sim T_{e r}$. The correlation coefficients computed from the sample of data are listed in table 2.

\begin{tabular}{|c|c|c|c|c|c|}
\hline Mode & $r_{P e, T s}$ & $r_{P e, T a}$ & $r_{P e, R H}$ & $r_{P e, T e r}$ & $r_{T s, T e r}$ \\
\hline Shore off & 0,48 & $-0,71$ & $-0,48$ & 0,83 & 0,16 \\
\hline Shore on & 0,63 & $-0,26$ & $-0,38$ & $-0,26$ & $-0,65$ \\
\hline Anchor & $-0,76$ & 0,89 & $-0,83$ & $-0,38$ & 0,62 \\
\hline Cruising & 0,24 & $-0,15$ & 0,26 & 0,20 & $-0,14$ \\
\hline Functional & 0,22 & 0,70 & $-0,75$ & 0,54 & 0,48 \\
\hline Total & 0,35 & $-0,30$ & $-0,29$ & 0,26 & $-0,47$ \\
\hline
\end{tabular}

Table 2. Values of $r$ for the different pairs of variables listed in the upper row. In the last line, for comparison, we also include the correlation taking into account the full set of data.

Since the energetic needs of the ship are rather different depending on the mode of operation, it is important to perform the statistical analysis separating the data of the shore on, shore off, anchor, cruising, and functional modes. From the data of table 2, the following comments can be made:

1. For the shore off and shore on modes, the values of $r$ relating the consumption and the temperature of sea water are positive. They are $r=0.48$ and $r=0.63$, respectively, indicating considerable correlations.

2. For the anchor mode, the greatest value of the correlation is between the consumption and the ambient temperature, with a value of $r=0.89$. This condition also presents considerable negative correlations between consumption and sea water temperature $(r=$ $-0.76)$ and between power consumption and relative humidity ( $r=-0.83$ ). However, it should be said that the anchor mode is the one with a smaller amount of data, see Fig. 7.

3. The cruising mode has low correlation values. The highest $|r|$ relates the electrical consumption and the relative humidity, with a value $r=0.26$.

4. For the functional mode, the highest $|r|$ correspond to a negative correlation between the electrical consumption and the relative humidity and a positive correlation between consumption and ambient temperature.

In general, the electricity consumption under the various operating modes is influenced by the environmental variables. Considering $r$ for the whole set of data, all correlations are found to be moderate, and one would conclude that the most important external factor is the 
temperature of sea water, followed by ambient temperature and relative humidity. On the other hand, the $T_{s}$ variable presents considerable positive correlations for the shore conditions, and especially for "shore on". This underscores the convenience of splitting the data sample in modes, since otherwise this effect would not be visible. In order to stress the correlation of sea water temperature with energy consumption in the shore on mode, we present a scatter plot in Fig. 8. The data used for the plot correspond to the second shore on period depicted in Fig. 7, around frame D. Using this set of data the Pearson correlation coefficient is 0.80 .

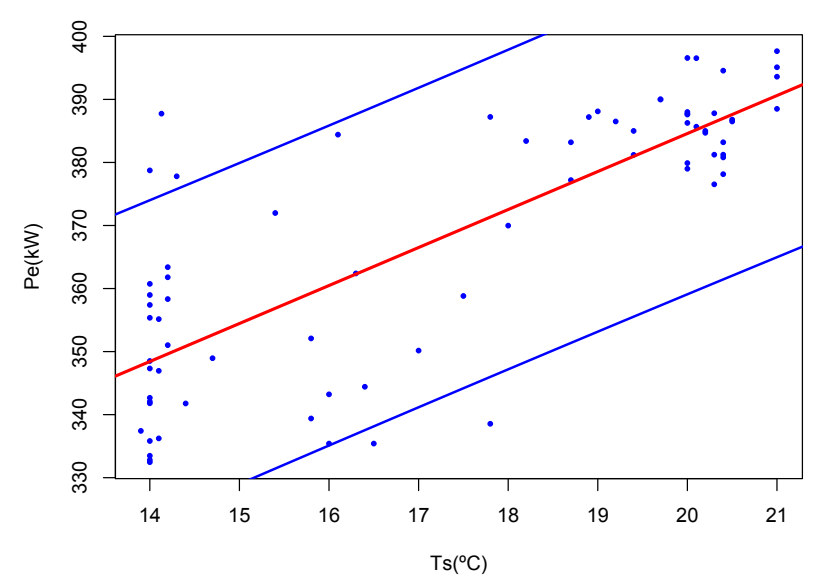

Figure 8. A scatter plot for the compared data of power consumption and sea water temperature for a subset of the data in shore on mode. The straight red line represents the best linear fit and the blue line the prediction intervals at $95 \%$ confidence level based on the linear regression model.

\section{Numerical simulation}

In order to estimate the thermal effect of the warship on the surrounding water, we have performed a numerical simulation of the temperature distribution of the system. The computation mimics the "shore on" condition, namely the ship is not moving but produces its own power and there are no water currents. As mentioned in the previous section, this might be related to some of the inferred correlations and it could have an impact for optimizing the energy consumption of the warship, as the "shore on" mode covers an important fraction of the lifetime of warships. Notice that computational models determining the temperature distribution due to the operation of ship engines can be instrumental in vessel design towards energetic optimization [26].

\section{Details on numerical computations}

The goal of the computation is to find the temperature distribution within the system (water, air, ship). In particular, the main interest is the temperature of the water surrounding the ship, which is static but with its electric generators and consumers working. This is done by numerically solving the heat equation:

$$
\rho C_{p}\left(\frac{\partial T}{\partial t}+\mathbf{u} \cdot \nabla T\right)=\nabla \cdot(k \nabla T)+Q
$$

where $T$ is temperature, $\mathbf{u}$ is the velocity vector, $\rho$ is the density of the fluid, $C_{p}$ is specific heat capacity at constant pressure, $t$ is time, $k$ is thermal conductivity and $Q$ describes the heat sources.

The numerical integration of the fluid equations was performed with the commercial SolidWorks ${ }^{\circledR}$ software. It uses a finite element method. A set of algebraic equations is generated by using a governing integral form that is integrated over a mesh of elements connected to nodes, that approximates the volume and surface of the bodies of interest. There is one equation for each node, where the unknown is the temperature [27]. Systems of linear equation arise and are solved with a preconditioned generalized conjugate gradient method [28].

An important issue is that of boundary conditions. In the borders of the simulation window, we have used Dirichlet boundary conditions. On the other hand, in the surface between the ship and the surrounding fluids, Neumann boundary conditions, corresponding to specified heat flux, are implemented. Thus, in our model we consider that the ship is surrounded by what is essentially an infinitely large volume of air and water and the transfer of heat from the vessel occurs via natural convection. We then assume that the temperature far away from the vessel is a constant, known value $T_{0}$.

The geometry of the F-105 frigate is shown in Fig. 9. The hull of the warship provides a constant heat flux at the base of the vessel and is modeled as a $25 \mathrm{~mm}$-thick steel surface of approximate dimensions $135 \mathrm{~m} \times 20 \mathrm{~m}$. The maximum height of the ship is $40 \mathrm{~m}$. The numerical domain is twice the dimensions of the ship in each direction. The used mesh includes 990,377 nodes and 700,037 elements with a maximum size of $1.0 \mathrm{~m}$ and a minimum size of $0.2 \mathrm{~m}$. It is depitcted in Fig. 9.

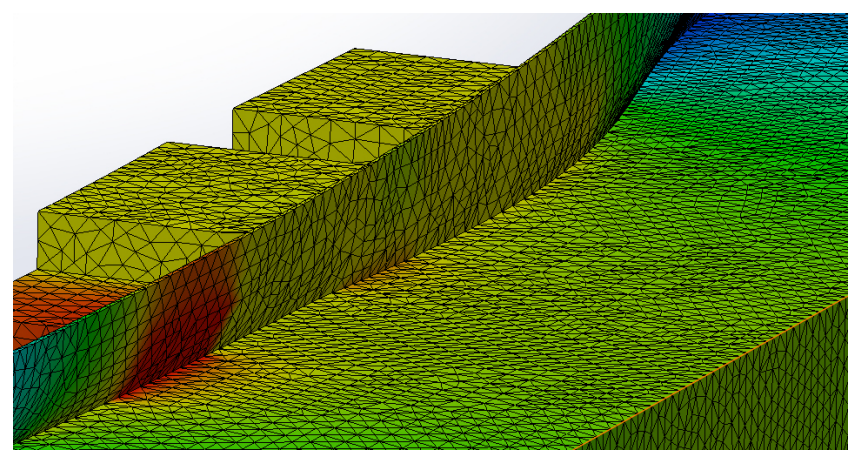

Figure 9. Geometry of the warship used for the numerical simulations, showing the computational grid in detail.

In heat transfer simulations, temperatures, temperature gradients and heat flux are calculated based on the generation of heat and conduction, convection and radiation phenomena. Set-point temperatures were assumed constant and set in each chamber of the vessel, based on actual data. In particular, this takes into account the operation of the different systems and consumers (including the electricity generators and the refrigerating systems), that affect the temperatures within the vessel. The study was carried out in steady state and the hull of the ship was modeled in alloy steel with a specific heat of $460 \mathrm{~J} \mathrm{~kg}^{-1} \mathrm{~K}^{-1}$. Heat transfer is modeled with a boundary condition for the heat flux $(q)$ of 
the form: $q=h \Delta T$, where $h$ is the heat transfer coefficient with value $50 \mathrm{~W} \mathrm{~m}{ }^{-2} \mathrm{~K}^{-1}$. Sea water has been considered as an infinite mass with a constant asymptotic temperature of $15^{\circ} \mathrm{C}$. The mechanisms of heat transfer taken into account are the solid-liquid conduction as well as the convection to the outside atmosphere with an average temperature of $10^{\circ} \mathrm{C}$. The convection coefficient of the air has been set at $20 \mathrm{~W}$ $\mathrm{m}^{-2} \mathrm{~K}^{-1}$. The result of the simulation is shown in Fig. 10 .

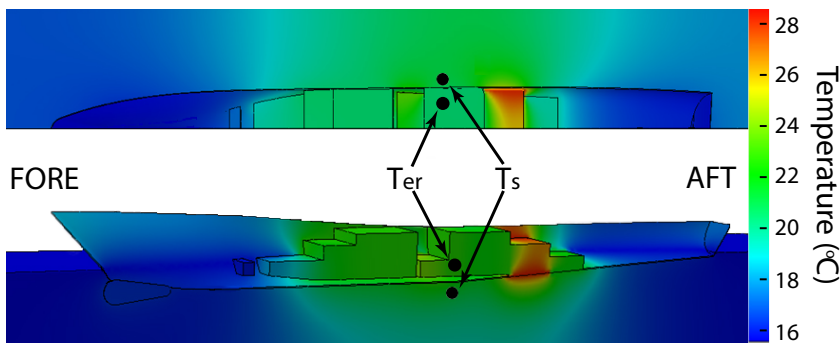

Figure 10. Numerical simulation of steady-state temperature distribution over a warship corresponding to the geometry of the F-105 frigate of Fig. 1 and its surrounding water, using the grid shown in Fig. 9. Top and bottom images correspond, respectively, to top and side views of the ship, which is in "shore on" mode. The black dots indicate two points where the calculated field takes the values $T_{e r}=23^{\circ} \mathrm{C}$ and $T_{s}=21^{\circ} \mathrm{C}$, which correspond to the engine room and seawater at the middle point of the temperature sensors (see Fig. 5). The results of the numerical simulation are in good agreement with data plotted in Fig. 7 (zone D). Other details of the simulation are given in the text.

The numerical uncertainties were investigated by modifying the number of nodes and elements, checking the gridindependence of the numerical solutions in order to ensure the accuracy and validity of the results [29]. In the test, three different grid systems were adopted with 428,942, 619,357 and 990,377 nodes and the Richardson extrapolation method was used to evaluate the truncation error [30]. In the third case, the extrapolated relative error and the finegrid convergence index [31] of the average temperature of the sea were around $0.034 \%$ and $0.045 \%$, respectively. Thus, the precision was satisfactory according to usual standards [32]. The computation was rechecked with a different commercial package (Comsol Multiphysics ${ }^{\circledR}$ ), finding minimal deviations.

Entering a single-valued heat transfer coefficient and using laminar flow can be considered as an oversimplification. Nevertheless, it is a good approximation for the case of a short-time heat exchange in an enclosed port under good weather conditions, where the velocities of water near the ship can be less than a few $\mathrm{cm} \cdot \mathrm{s}^{-1}$ [33]. With the proper $h$, the results of the simulation compare well with the experimental values [34]. A wider range of cases could be covered with more sophisticated approaches [35].

\section{Analysis of the results}

The computation of this section corresponds to a simple modeling of the "shore on" mode of the warship: the vessel is static but the aft electricity generator remains active in order to provide power to the HVAC and to the rest of consumers. It can be appreciated in Fig. 7 (frame D) that in the "shore on" mode, the sea water temperature $\left(T_{s}\right)$ rises from an almost constant value $14.4 \pm 0.3^{\circ} \mathrm{C}$ to an asymptotic temperature of $20.1 \pm 0.5^{\circ} \mathrm{C}$ (the means and standard deviations are computed from the data of Fig. 7). This can be compared to the result of Fig. 10, where $T_{s}$ should be identified with the average value of the water temperature at the position of the two sea chests where the sensors are placed. The value obtained from the simulation is $21^{\circ} \mathrm{C}$, which is in good agreement with the data from Fig. 7 (zone D).

\section{Relating statistics and numerics: an estimation of potential energy savings}

The numerical analysis shows that the temperature around a static ship in "shore on" mode can be expected to noticeably increase. This is presumably the cause of the rise in sea water temperature in the frame D of Fig. 7. On the other hand, in the same frame, the power consumption increases by approximately $10 \%$. This coincidence is related to the large positive value of $r_{P e, T s}$ of table 2 and to the correlation depicted in Fig. 8. A plausible (partial) explanation of the large positive correlation in the shore mode is that the water coming in through the sea chests, see Fig. 5, is warmed by the energy generated by the ship itself. Since that water is used for refrigeration, an entrance of tepid water means reduced efficiency. This indicates sea water temperature and energy consumption can positively feed back each other.

Figure 10 shows that the temperature increase is not spatially uniform around the ship. Modifying the position of the sea chests would affect the temperature of the incoming water and, according to the previous discussion, it can have an impact in energy expenditures.

It is interesting to provide a quantitative estimate of the effect. The power consumption increases in frame D, approximately, from $328 \mathrm{~kW}$ to $385 \mathrm{~kW}$. Assuming that half of the life cycle of the warship is spent at port, this amounts to $0.25 \times 10^{6} \mathrm{kWh}$ per year (corresponding to a carbon footprint of 78 tons $\mathrm{CO}_{2}$ ), around $5 \%$ of the HVAC consumption or $2 \%$ of the total electric consumption of the vessel estimated above. This is a gross estimation of the potential energy savings that could be achieved with a more adequate design.

\section{Conclusions}

EE [36] in considered as an increasingly important goal for naval engineering. The International Maritime Organization (IMO) has defined two indicators: the Energy Efficiency Design Index (EEDI) and the Energy Efficiency Operational Indicator (EEOI) for addressing efficiency and $\mathrm{CO}_{2}$ emissions. Measuring tools are important for implementing emission control policies and management plans [37]. The evaluation of these indices for particular vessels is of interests [38] and sophisticated mathematical tools have been proposed to properly assess the reliability and carbon footprint of a shipping link [23].

In this framework, the efficiency of the electric generators [39] is an essential ingredient. On the other hand, the analysis of real data of energy expenditure in comparison with external variables can provide key information in relation with potential improvements for reducing the electric consumption. The goal of the present work has been to take a step in this direction, mainly focusing on the 
particular aspects of warships that contrast with the more studied merchant ships. The following conclusions have been derived:

- Auxiliary systems account for a major fraction of the installed power for consumers and of actual electricity consumption. Among them, the HVAC (group 510) load represents the most important part.

- It is important to make a clear discrimination between the different operating modes. As shown in table 2, Pearson correlations between a pair of variables can be very disparate for different modes.

- The temperature of sea water is an important parameter in the study of electric power consumption and the HVAC in particular, cf. Fig. 8. Considerable correlations have been found between these two variables for several operating conditions, including a value of 0.63 for the shore on condition.

- In port, the vessel itself can noticeably heat the water around it. It may be important to take this fact into account in the design, when placing the sea chests and water inlets for the HVAC. These comments are especially important for warships, as compared to merchant ships, because they spend longer periods at port. For the studied warship, a gross estimation of the annual energy savings that might be achieved by taking this issues into account for the design is 0.25 $\times 10^{6} \mathrm{kWh}$.

The typical systems installed in vessels are very general and do not respond to the reality of the diversity of situations warships find throughout their life cycle. This contribution provides a first step for the specialized statistical analysis of procedures, with particular attention to HVAC systems.

\section{Acknowledgements}

The authors thank the Spanish Navy for its kind cooperation.

\section{Declaration of Conflicting Interests}

The Authors declare that there is no conflict of interest.

\section{Funding}

This work was supported by Xunta de Galicia [grant number GPC2015/019]; and by Ministerio de Economía y Competitividad [grant numbers FIS2014-58117-P, FPDI2013-17516, ENE2013-48015-C3-1-R].

\section{References}

[1] Sharifi Y, Ghassemi $\mathrm{H}$ and Zanganeh $\mathrm{H}$. Various innovative technologic devices in shipping energy saving and diminish fuel consumption. International Journal of Physics 2017; 5(1): 21-29.

[2] Saunders S (ed.) Jane's fighting ships 2016-2017. IHS Markit., 2016.

[3] Jafarzadeh S and Utne IB. A framework to bridge the energy efficiency gap in shipping. Energy 2014; 69: 603-612.
[4] Papanikolaou A, Zaraphonitis G, Bitner-Gregersen E et al. Energy efficient safe ship operation (SHOPERA). Transportation Research Procedia 2016; 14: 820-829.

[5] Arce ME, Saavedra Á, Míguez JL et al. The use of grey-based methods in multi-criteria decision analysis for the evaluation of sustainable energy systems: A review. Renewable and Sustainable Energy Reviews 2015; 47: 924-932.

[6] O'Rourke R. Electric-drive Propulsion for US Navy ships: Background and issues for Congress. Congressional Research Service, The Library of Congress 2000; .

[7] Stepanchick J and Brown A. Revisiting DDGX/DDG51 Concept Exploration. Naval Engineers Journal 2007; 119(3): 67-88.

[8] Young S, Newell J and Little G. Beyond electric ship. Naval engineers journal 2001; 113(4): 79-92.

[9] O'Rourke R. Navy Ship Propulsion Technologies: Options for Reducing Oil Use-Background for Congress. Congressional Research Service, The Library of Congress 2006; .

[10] Tillig F, Ringsberg J, Mao W et al. A generic energy systems model for efficient ship design and operation. Proceedings of the Institution of Mechanical Engineers, Part M: Journal of Engineering for the Maritime Environment 2017; 231(2): 649-666.

[11] Ballou PJ. Ship energy efficiency management requires a total solution approach. Marine Technology Society Journal 2013; 47(1): 83-95.

[12] Reddy TA. Applied data analysis and modeling for energy engineers and scientists. Springer Science \& Business Media, 2011.

[13] Creutzig F, Baiocchi G, Bierkandt R et al. Global typology of urban energy use and potentials for an urbanization mitigation wedge. Proceedings of the National Academy of Sciences 2015; 112(20): 62836288.

[14] Mueller L, Jakobi G, Czech H et al. Characteristics and temporal evolution of particulate emissions from a ship diesel engine. Applied Energy 2015; 155: 204-217.

[15] Perera LP and Mo B. Data analysis on marine engine operating regions in relation to ship navigation. Ocean Engineering 2016; 128: 163-172.

[16] Bialystocki N and Konovessis D. On the estimation of ship's fuel consumption and speed curve: A statistical approach. Journal of Ocean Engineering and Science 2016; 1(2): 157-166.

[17] Lepore A, Reis MS, Palumbo B et al. A comparison of advanced regression techniques for predicting ship co2 emissions. Quality and Reliability Engineering International 2017; 33(6): 1281-1292. 
[18] Watson DG. Practical ship design, volume 1. Gulf Professional Publishing, 2002.

[19] Banks C, Turan O, Incecik A et al. Understanding ship operating profiles with an aim to improve energy efficient ship operations. In Proceedings of the Low Carbon Shipping Conference 2013, London. pp. 1-11.

[20] Doerry N and Moniri K. Specifications and standards for the electric warship. In Electric Ship Technologies Symposium (ESTS), 2013 IEEE. IEEE, pp. 21-28.

[21] Doerry N. Electric power load analysis. ASNE Naval Engineers Journal 2012; 124(4): 45-48.

[22] Department of the Navy: Naval Sea System Command. DDS 310-1 Rev.1: Electric power load analysis (EPLA). Washington DC, USA 2012;

[23] Coraddu A, Figari $M$ and Savio S. Numerical investigation on ship energy efficiency by Monte Carlo simulation. Proceedings of the institution of mechanical engineers, part M: journal of engineering for the maritime environment 2014; 228(3): 220-234.

[24] NATO. ANEP-41. Ship costing. Allied Naval Engineer Publication 2016; .

[25] Hernández CR, Fernández R, Arce ME et al. Análisis del ciclo de vida en Fragatas de la serie F-100. IV Congreso Nacional de $I+D$ en Defensa y Seguridad 2016; : 279-285.

[26] Orosa JA, Costa ÁM and Pérez JA. A new modelling procedure of the engine room ventilation system for work risk prevention and energy saving. Proceedings of the Institution of Mechanical Engineers, Part M: Journal of Engineering for the Maritime Environment 2017; 231(4): 863-870.

[27] Akin JE. Finite element analysis concepts: via SolidWorks. World Scientific Publishing Company, 2010.

[28] Saad Y. Iterative methods for sparse linear systems, volume 82. siam, 2003.

[29] Celik I and Karatekin O. Numerical experiments on application of richardson extrapolation with nonuniform grids. Journal of fluids engineering 1997; 119(3): 584-590.

[30] Richardson LF. Ix. the approximate arithmetical solution by finite differences of physical problems involving differential equations, with an application to the stresses in a masonry dam. Phil Trans $R$ Soc Lond A 1911; 210(459-470): 307-357.

[31] Roache PJ. Verification and validation in computational science and engineering, volume 895. Hermosa Albuquerque, NM, 1998.

[32] Roache PJ, Ghia KN and White FM. Editorial policy statement on the control of numerical accuracy. Journal of Fluids Engineering 1986; 108(1): 2-2.
[33] De Marchis M, Freni G and Napoli E. Threedimensional numerical simulations on wind-and tideinduced currents: The case of augusta harbour (italy). Computers \& Geosciences 2014; 72: 65-75.

[34] Falconer R and Yu G. Effects of depth, bed slope and scaling on tidal currents and exchange in a laboratory model harbour. Institution of Civil Engineers Proceedings pt 2 1991; 91: 561-76.

[35] Xie MX and Zhang W. Numerical study on the threedimensional characteristics of the tidal current around harbor entrance. Journal of Hydrodynamics, Ser B 2010; 22(6): 847-855.

[36] Patterson MG. What is energy efficiency?: Concepts, indicators and methodological issues. Energy policy 1996; 24(5): 377-390.

[37] Figari M, D’Amico M and Gaggero P. Evaluation of ship efficiency indexes. In Sustainable Maritime Transportation and Exploitation of Sea Resources, volume 621. ROUTLEDGE in association with GSE Research, 2011. pp. 621-627.

[38] Tran TA. A research on the energy efficiency operational indicator eeoi calculation tool on $\mathrm{m} / \mathrm{v}$ nsu justice of vinic transportation company, vietnam. Journal of Ocean Engineering and Science 2017; 2(1): 55-60.

[39] Figari $M$ and Soares CG. Fuel consumption and exhaust emissions reduction by dynamic propeller pitch control. Proc MARSTRUCT 2009, Lisbon, 16-18 March 2009 2009; . 